\title{
Correcting fresh grass allowance for rejected patches due to excreta in intensive grazing systems for dairy cows
}

\author{
Cindy W. Klootwijk, ${ }^{1 *}$ Gertjan Holshof, ${ }^{2}$ Imke J. M. de Boer, ${ }^{1}$ Agnes Van den Pol-Van Dasselaar, ${ }^{2,3}$ Bas Engel, ${ }^{4}$ \\ and Corina E. Van Middelaar ${ }^{1}$ \\ ${ }^{1}$ Animal Production Systems group, Wageningen University \& Research, PO Box 338, 6700 AH Wageningen, the Netherlands \\ ${ }^{2}$ Wageningen Livestock Research, Wageningen University \& Research, PO Box 338, 6700 AH Wageningen, the Netherlands \\ ${ }^{3}$ Aeres University of Applied Sciences, De Drieslag 4, $8251 \mathrm{JZ}$ Dronten, the Netherlands \\ ${ }^{4}$ Biometris, Wageningen University \& Research, PO Box 16, 6700 AA Wageningen, the Netherlands
}

\section{ABSTRACT}

Dairy farms with intensive grazing systems combine grazing with supplemental feeding, which can be challenging because an incorrect balance between fresh grass allowance and feed supplementation results in inefficient use of the pasture, lower feed efficiency, and potential decreases in animal production. When estimating fresh grass allowance, we currently do not correct for the formation of rejected patches (RP) surrounding excreta, which can lead to overestimation of the potential fresh grass intake and hampers optimal grazing. In this study, therefore, we aim to quantify the formation of RP in intensive grazing systems and improve the quantification of fresh grass allowance. To do so, we studied 2 grazing systems (i.e., compartmented continuous grazing and strip grazing) that differ in key grazing characteristics, such as pre- and post-grazing heights and period of regrowth. The experiment was performed from April to October in 2016 and 2017 with 60 dairy cows at a fixed stocking rate of 7.5 cows/ha. Average pre-grazing grass height was measured with a rising plate meter. To quantify the formation of RP after grazing, individual grass height measurements were conducted after grazing and classified as RP or not, based on visual assessment. Our analysis showed that the average percentage of grassland covered with $\mathrm{RP}$ increased from around $22 \%$ at the end of May to around $43 \%$ at the end of July/beginning of August, and these percentages do not differ across grazing systems. The percentage of grassland covered with RP should be subtracted from the total grazed area to better estimate true fresh grass allowance.

Key words: intensive grazing, fresh grass allowance, rejected patches, rising plate meter

Received December 7, 2018.

Accepted June 20, 2019.

*Corresponding author: cindy.klootwijk@wur.nl

\section{INTRODUCTION}

Grazing can be considered a key component of public opinion of the dairy sector. Dutch society, for example, appreciates an open landscape with grazing cows (Van den Pol-van Dasselaar et al., 2008; Boogaard et al., 2010) and associates grazing with sustainable milk production and animal welfare (Blokland et al., 2017). In addition to societal benefits, grazing can also have economic benefits. Various milk processors pay a higher milk price to farmers who graze their cows on pasture (Doornewaard et al., 2017). Furthermore, several studies have shown that the economic benefit of grazing increases with an increase in fresh grass intake per cow, due to lower costs for supplementary feed and contract labor (Finneran et al., 2012; Meul et al., 2012; Van den Pol-van Dasselaar et al., 2014).

A reliable prediction of the fresh grass allowance can increase farm profit by optimizing the grazing regimen. In an optimum grazing regimen, fresh grass allowance matches the requirements of the herd, which may increase grazing efficiency and reduce variations in DMI and hence fluctuations in milk production (Hennessy et al., 2015). Fresh grass allowance is determined by stocking rate and available herbage mass (HM) on the grazing platform (Stockdale and King, 1983). The stocking rate on the grazing platform can be calculated by dividing the number of cows by the available hectares of grassland available and accessible for grazing. Herbage mass can be indirectly measured with the rising plate meter (RPM; Sanderson et al., 2001), which is used in practice to measure grass height before grazing and is subsequently translated to HM by using a prediction equation. Using this method, the fresh grass allowance can be estimated before grazing. The HM $<4 \mathrm{~cm}$ is not considered to be part of the fresh grass allowance because cows do not graze the stubble (Kennedy et al., 2007). In practice, however, the offered fresh grass is not homogeneously grazed down due to selective grazing. 
Excreta is the major cause of selective grazing as cows refuse to graze grass contaminated by dung due to the smell and taste, which results in the formation of rejected patches (RP; Dohi et al., 1991; Bosker et al., 2002; Verwer et al., 2016). Marten and Donker (1964) found that $93 \%$ of the nongrazed areas contained dung from previous grazing events. In addition, $81 \%$ of the dung patches, deposited 3 to $4 \mathrm{wk}$ before grazing, were rejected by dairy cows during grazing. Similarly, urine can result in RP and persist for many months (Dennis et al., 2011). When estimating fresh grass allowance, dairy farmers currently do not correct for the formation of RP. This overestimates the fresh grass allowance and, thereby, the potential fresh grass intake of dairy cows, which can undermine optimal grazing.

The excreta load and distribution in the field and, thereby, the formation of RP is shown to be influenced by stocking rate (Arnold and Holmes, 1958; Dennis et al., 2011). The stocking rate on the grazing platform (i.e., the grassland accessible and available for grazing) is expected to increase in the Netherlands from 3.5 dairy cows/ha in 2013 to 4.5 in 2020 (Van den Pol-van Dasselaar et al., 2015). This has resulted in reduced (daily) fresh grass allowance per cow and the need to increase feed supplementation. In this study, therefore, we aim to quantify the formation of RP in intensive grazing systems and improve the quantification of fresh grass allowance. To do so, we studied 2 grazing systems [i.e., compartmented continuous grazing (CCG) and strip grazing $(\mathbf{S G})]$ that differ in key grazing character- istics, such as pre- and post-grazing sward heights and period of regrowth. In addition, these 2 systems are examples of daily rotational grazing systems suitable for intensive Dutch dairy farms with feed supplementation (Holshof et al., 2018).

\section{MATERIALS AND METHODS}

\section{Grazing Systems}

The grazing experiment in which we conducted our measurements was performed at the Dairy Campus research facility in Leeuwarden in 2016 and 2017. Sixty dairy cows were allocated to 2 different grazing systems (i.e., CCG and SG) in 2 replicates (Figure 1). Cows were stratified based on parity (first, second, and higher parity number), DIM, milk constituent yield, and fat- and protein-corrected milk yield to ensure a balanced distribution of the cows. The cows were randomly allocated to the 4 treatment groups, resulting in a randomized complete design. Cows had an average lactation number $( \pm \mathrm{SD})$ of $2.5 \pm 1.2$ (16 primiparous and 44 multiparous) in 2016 and $2.6 \pm 1.4$ (12 primiparous and 48 multiparous) in 2017. Body weight was on average $582 \pm 67 \mathrm{~kg}$ in 2016 and $617 \pm 73 \mathrm{~kg}$ in 2017 .

All cows calved in the period December to March, before the grazing season. In total we used 8 ha of grassland, implying a fixed stocking rate of 7.5 cows per ha of grazing area (classified as intensive grazing). Standard grazing time was from 0830 until 1600

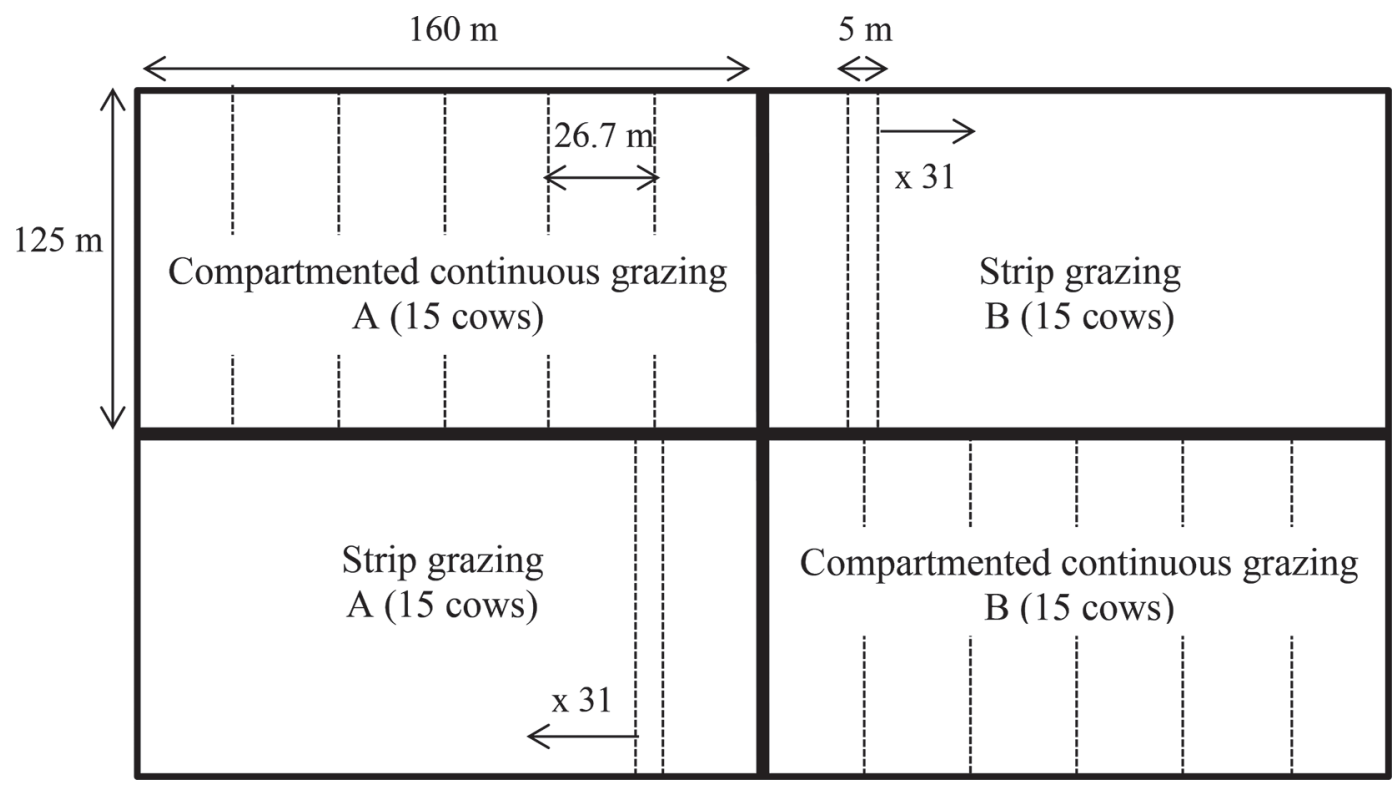

Figure 1. Overview of the grazing experiment with 2 contrasting grazing systems-compartmented continuous grazing (CCG) and strip

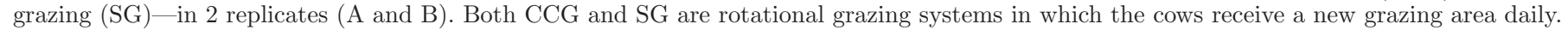
In our experiment cows rotated across 6 compartments in the CCG system and cows rotate across 31 strips in the SG system. 
h. Cows had access to the pasture between morning and afternoon milking and were housed indoors in a cubicle barn during the rest of the time, where they were supplemented with roughage and concentrates. The botanical composition of the fields was $72 \%$ perennial ryegrass (Lolium perenne L.), $12 \%$ timothy grass (Phleum pratense L.), 11\% rough meadow-grass (Poa trivialis L.), and $5 \%$ other species.

Both CCG and SG are rotational grazing systems in which the cows receive a new grazing area daily. These systems, however, largely differ in key grazing characteristics, such as pre- and post-grazing sward heights and period of regrowth. Each CCG replicate was 2 ha and was divided into six 0.33-ha compartments. On a grazing day, therefore, each cow had access to $222 \mathrm{~m}^{2}$ of fresh grass. Each SG replicate was also 2 ha and was divided into 31 strips of 0.07 ha each. On a grazing day, each cow had access to $43 \mathrm{~m}^{2}$ of fresh grass and the strip of the previous day to provide more space to walk (in total $86 \mathrm{~m}^{2}$ ).

For CCG, 5 compartments were grazed and (random) the sixth one was cut for silage to remove RP. After regrowth (on average $10 \mathrm{~d}$ ) the sixth compartment was added to the rotation to provide fresh grass for grazing and the next compartment was selected to produce grass for silage. So during the whole season, 5 of the 6 compartments were grazed in a 5 -d rotation. Period of regrowth for the 5 compartments in the rotation, therefore, was $4 \mathrm{~d}$ for CCG. For SG, blocks of 4 strips were cut for silage and to remove RP after 2 grazing events. After regrowth, the cut strips were again added to the rotation. Period of regrowth was on average $20 \mathrm{~d}$ for SG. Cutting for silage in between grazing events is a common practice on Dutch dairy farms and reduces seasonal buildup of RP.

The period of regrowth influenced the fresh grass allowance in CCG and SG, depending on the grass growth (influenced by weather conditions). Fresh grass allowance was measured by performing weekly grass height measurements in all compartments and strips. Per compartment or cluster of 4 strips, about 60 measurements were performed while walking in a $\mathrm{W}$ shape through the compartments and strips.

Based on the fresh grass allowance, the amount of roughage supplementation was adjusted to provide sufficient feed for cows on pasture. Total DMI was set at $21 \mathrm{~kg}$ of $\mathrm{DM} /$ cow per day and the concentrate allowance was fixed at $5.4 \mathrm{~kg}$ of $\mathrm{DM} / \mathrm{cow}$ per day. Roughage supplementation was at least $5.0 \mathrm{~kg}$ of $\mathrm{DM} /$ cow per day, with a maximum of $8.0 \mathrm{~kg}$ of $\mathrm{DM}$ of maize silage supplemented with grass silage according to requirements. In addition to the adjustment of supplementary feeding, daily grazing time was reduced by $2 \mathrm{~h}$ when total grass height was below $60 \mathrm{~mm}$ for CCG to ensure sufficient grass growth for the next grazing. For SG, to match daily grazing time with grass allowance, grazing time was reduced by $2 \mathrm{~h}$ when fresh grass allowance was below $4.0 \mathrm{~kg}$ of $\mathrm{DM} / \mathrm{cow}$ per day.

\section{Quantifying Fresh Grass Allowance with RP Correction}

Because the formation of RP occurs during grazing, we analyzed the percentage of grassland covered with $\mathrm{RP}$ after grazing to correct fresh grass allowance before grazing. We recorded grass heights in recently grazed fields and indicated for each individual measurement whether or not it corresponded to an RP (yes/no) based on visual assessment. An RP was identified as an ungrazed spot due to excreta (Bao et al., 1998). The percentage of grassland measurements related to a RP was determined by the mean proportion of $\mathrm{RP}$ and non-RP according to the visual assessment. In total we analyzed 9 fields for CCG and 8 fields for SG. Proportions of RP per field were analyzed with a logistic regression model. This model consisted of main effects and interactions for the 2 systems and for 3 time periods ( $1=$ May, $2=$ July, and $3=$ August $)$ on the logit scale. A multiplicative overdispersion parameter was included in the binomial variance function. Parameters on the logit scale were estimated by maximum quasi-likelihood (McCullagh and Nelder, 1989). The overdispersion parameter was estimated by Pearson's chi-squared statistic divided by its degrees of freedom. A test for interaction and tests for main effects (within the additive model without interaction) were based on the quasi-likelihood ratio test. $P$-values were derived from an approximation with an $F$-distribution (with denominator degrees of freedom associated with Pearson's chi-squared from the largest model). Pairwise comparisons between time points, within the additive model, were based on quasi-Wald tests, with $P$-values derived from an approximation with the t-distribution. Calculations were performed with generalized linear model facilities of Genstat (VSN International, 2017).

\section{Grass Height Measurements}

To ensure a reliable representation of the RP formation per field, we used the following protocol. The fields served as experimental units and were either a compartment of CCG or 2 adjacent strips of SG. For CCG, one compartment measured $26.7 \times 125 \mathrm{~m}(3,333$ $\left.\mathrm{m}^{2}\right)$. In this compartment, we marked the long side at about every $15 \mathrm{~m}$ with a stick and walked through the compartment in a W-pattern, taking 30 measurements in each of the $4 \mathrm{~W}$-shapes covering $30 \mathrm{~m}$ (Figure 2A), resulting in 120 measurements. Measurements were 
done in triplicate to have a total of 360 measurements per compartment. For SG, 2 adjacent strips measured a total size of $10 \times 125 \mathrm{~m}$. In these strips, we marked the long side in between the 2 strips at about every $15 \mathrm{~m}$ with a stick and walked through the middle of each strip straight from the beginning until the end, taking about 15 measurements per $30 \mathrm{~m}$ (Figure 2B). Measurements were done in triplicate to have a total of 360 measurements per 2 strips.

In total we conducted 6,120 grass height measurements in 17 recently grazed fields, from the end of May until the beginning of August in 2017. We calculated the average grass height for RP and non-RP for in total 9 fields for CCG and 8 fields for SG and performed a Wilcoxon's signed rank test to compare the grass height of RP and non-RP for CCG and SG separately. All grass height measurements were conducted by the same operator using the Jenquip EC20 (NZ Agriworks Ltd., Feilding, New Zealand) RPM, which was developed in New Zealand. This RPM enables the operator to record each individual grass height measurement in millimeters and was connected with an Android Pasture Meter App via a Bluetooth connection.

\section{Quantifying the Required Number of Grass Height Measurements Per Field}

The current advice in practice is to take 30 measurements per field before grazing to estimate fresh grass allowance. To determine whether 30 measurements is sufficiently accurate to estimate HM in intensive grazing systems, we analyzed the effect of number of grass height measurements on the accuracy of estimating the average grass height in the field. Equation [1] was used to quantify the effect of within-field variance on the number of measurements needed per field to estimate the average grass height with a predefined, accepted accuracy (i.e., error). Because the accepted error in millimeters depends on the average grass height and the aim of measuring, we varied the accepted error from 1 to $20 \mathrm{~mm}$.

$$
\mathrm{n}=\frac{1.96^{2} \times \sigma^{2}}{\mathrm{E}^{2}}
$$

Here, $\mathrm{n}$ is the number of measurements, $\sigma^{2}$ is the withinfield variance between measurements and $\mathrm{E}$ is the error margin in grass height.

To determine the number of measurements needed to estimate grass height before grazing (equation [1]), we need an estimate of the within-field variance in grass height for both CCG and SG. Because the average grass height to quantify $\mathrm{HM}$ is measured before grazing in
A. $\mathrm{CCG}$
B. SG
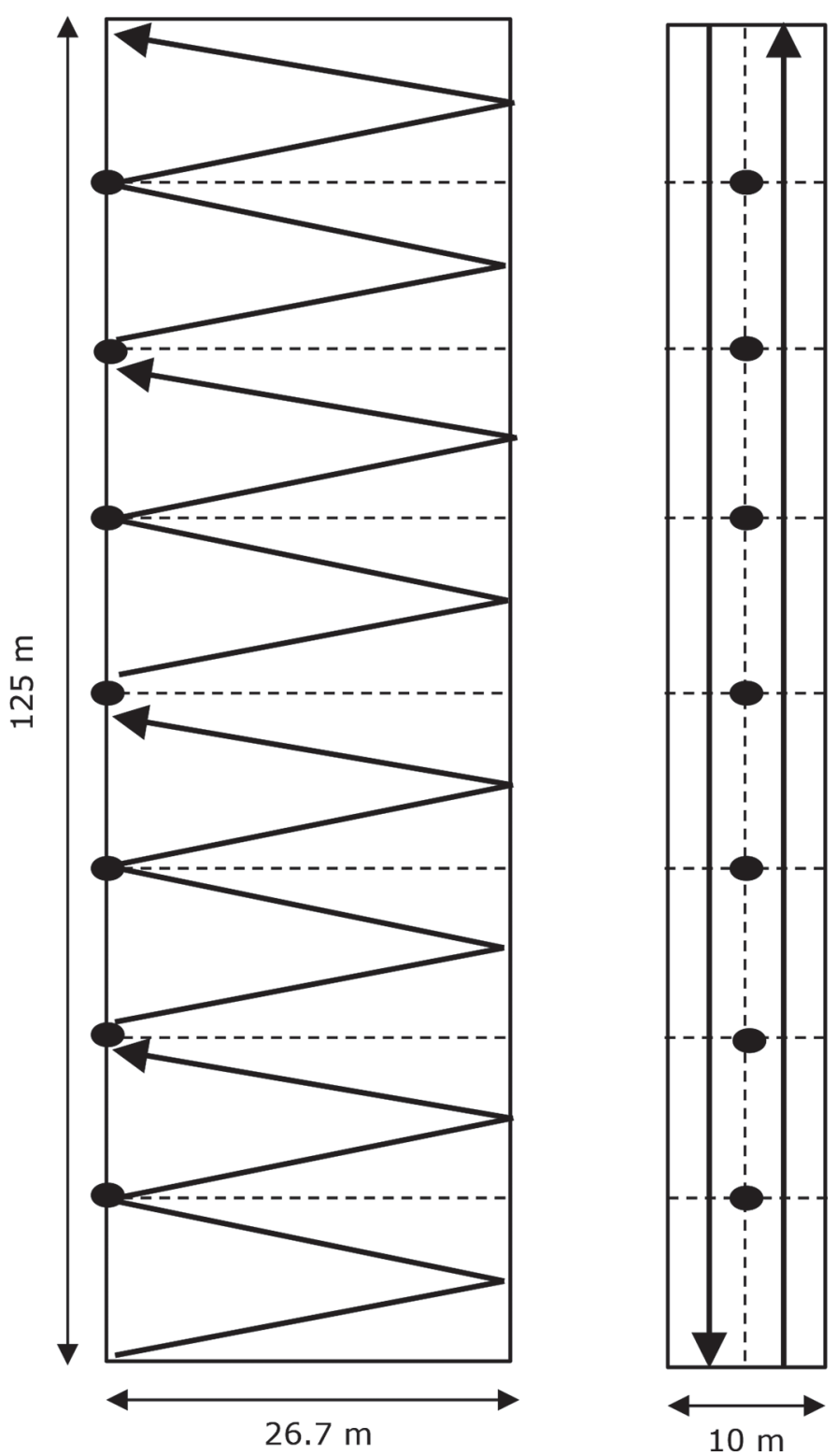

Figure 2. Sampling technique for representative grass height measurements in 2 grazing systems: $(A) C C G=$ compartmented continuous grazing, and (B) SG = strip grazing, with the black dots indicating the sticks as reference points.

practice, we needed a representative within-field variance for before grazing. For both systems, therefore, we conducted additional measurements in 3 fields that were not grazed since the last mowing activity, with 360 measurements per field. For CCG, the within-field variation in grass height before and after grazing is not so different because the period of regrowth is only $4 \mathrm{~d}$. In addition, the within-field variation in grass height 
increases as the number of grazing events increases. Therefore, we also included the within-field variation of the fields after grazing providing an average withinfield variance after 0 to 18 grazing events for CCG. Since we argue that the fresh grass allowance should be corrected for RP, we excluded RP from this analysis.

\section{RESULTS AND DISCUSSION}

\section{Fresh Grass Allowance with RP Correction}

Figure 3 shows the variation in grass height per recently grazed field for non-RP and RP, for each grazing system separately. For non-RP, average grass height per field was $65 \pm 18 \mathrm{~mm}$ for CCG and $64 \pm 18 \mathrm{~mm}$ for SG. For RP, average grass height per field after grazing was higher than for non-RP $(P<0.001$; i.e., $142 \pm 34 \mathrm{~mm}$ for CCG and $106 \pm 23 \mathrm{~mm}$ for SG). The large contrast in grass height between non-RP and RP supports that we could distinguish them based on visual assessment. The contrast we found in grass height of non-RP and $\mathrm{RP}$ is comparable with results of Bao et al. (1998), who showed an average postgrazing grass height of $60 \mathrm{~mm}$ for non-RP and $100 \mathrm{~mm}$ for RP in a 20-d rotational system with a stocking rate of 4.9 cows/ha. Schwinning and Parsons (1999) argued that instead of having 2 alternative stable states (i.e., predominantly shorter or taller patches), a grazing system with a preference for short patches (non-RP) is likely to result in a bimodal frequency distribution with short (non-RP) and tall (RP) patches. In line with this, Bao et al. (1998) mentioned that the extent to which tall patches are defoliated seems likely to be influenced by the grazing pressure. Cows first tend to graze on non-RP, but then turn to RP gradually in proportion to the availability when the sward is further grazed down (Bao et al., 1998). The shift toward RP is likely dependent on the proportion of available leaf to stem material, because cows prefer leaf over stem material. The RP in CCG likely contain more stem material since they are refused for multiple grazing events without mowing in between.

Our analysis showed that the average percentage of grassland (predominantly perennial ryegrass) covered with RP increased from around $22 \%$ at the end of May to around $43 \%$ at the end of July/beginning of August (Figure 4). The logistic regression model showed that the development of proportion of RP in time did not differ across grazing systems $(P=0.33)$. Time showed an effect on the proportion of RP $(P<0.001)$, whereas grazing system did not $(P=0.33)$. Pairwise comparisons between time points revealed that the proportion of RP was lower in May compared with both July and August $(P<0.001)$, but that the difference between July and August was not significant $(P=0.37)$. These results suggest that the percentage of grassland covered with RP is not influenced by grazing system under intensive grazing. In addition, after a period of increase in grassland covered with RP, in both systems a maximum seems to be reached in July. MacLusky (1960) also described an equilibrium state after an increase in RP formation, which can be explained by a balance between formation of RP and reduction of $\mathrm{RP}$ due to breakdown of dung.

It takes on average about 3 mo before the dung patches have visually disappeared from the pasture (Lantinga et al., 1987). It may take about $2 \mathrm{yr}$, however, before the affected areas are fully recolonized with the original grass species and grazed normally again (Castle and MacDaid, 1972). The time of disappearance of dung patches depends on weather conditions, the activity of the soil fauna, feeding strategy, and mechanical treatment (Lantinga et al., 1987; Bosker et al., 2002; Vadas et al., 2011; Van Schooten et al., 2014). The time to reach equilibrium in the percentage of grassland covered with $\mathrm{RP}$ as well as the level of this equilibrium, therefore, will likely depend on these factors. Grass species might also influence the area covered with RP. We observed that in early spring the whole field was equally grazed. In line with perennial ryegrass, however, timothy grass was more often rejected by the cows in June. With the grass species being equally distributed in the field, we do not expect a marked effect of the botanical composition of the fields in this study on the proportion of grassland covered with RP.

Sanderson et al. (2001) concluded that measuring within 10\% error margin can improve forage budgeting by allocating an adequate amount of grass to the herd. An error margin of 22 to $43 \%$ in predicting fresh grass allowance is substantial and can result in an imbalance with the rest of the ration and subsequently a reduction in milk production. If the fresh grass allowance is insufficient in the CCG system, the grass height will decrease below the intended $60 \mathrm{~mm}$, which will result in an insufficient grass growth. This means that less grass will be left for the next grazing and this will increase the need for supplementary feeding. The SG system is even less flexible because insufficient grass will be available to feed the cows, requiring an immediate increase in supplementary feeding. Therefore, it is necessary to correct fresh grass allowance for RP formation under intensive grazing. The fresh grass allowance can be corrected by subtracting the surface covered with RP from the total grazed area. If the RP can be visually distinguished before grazing, they should be excluded from the grass height measurements to get a reliable estimate of the remaining grazing area without RP. This is more relevant for grazing systems with a short grazing interval (i.e., CCG) because the contrast in 

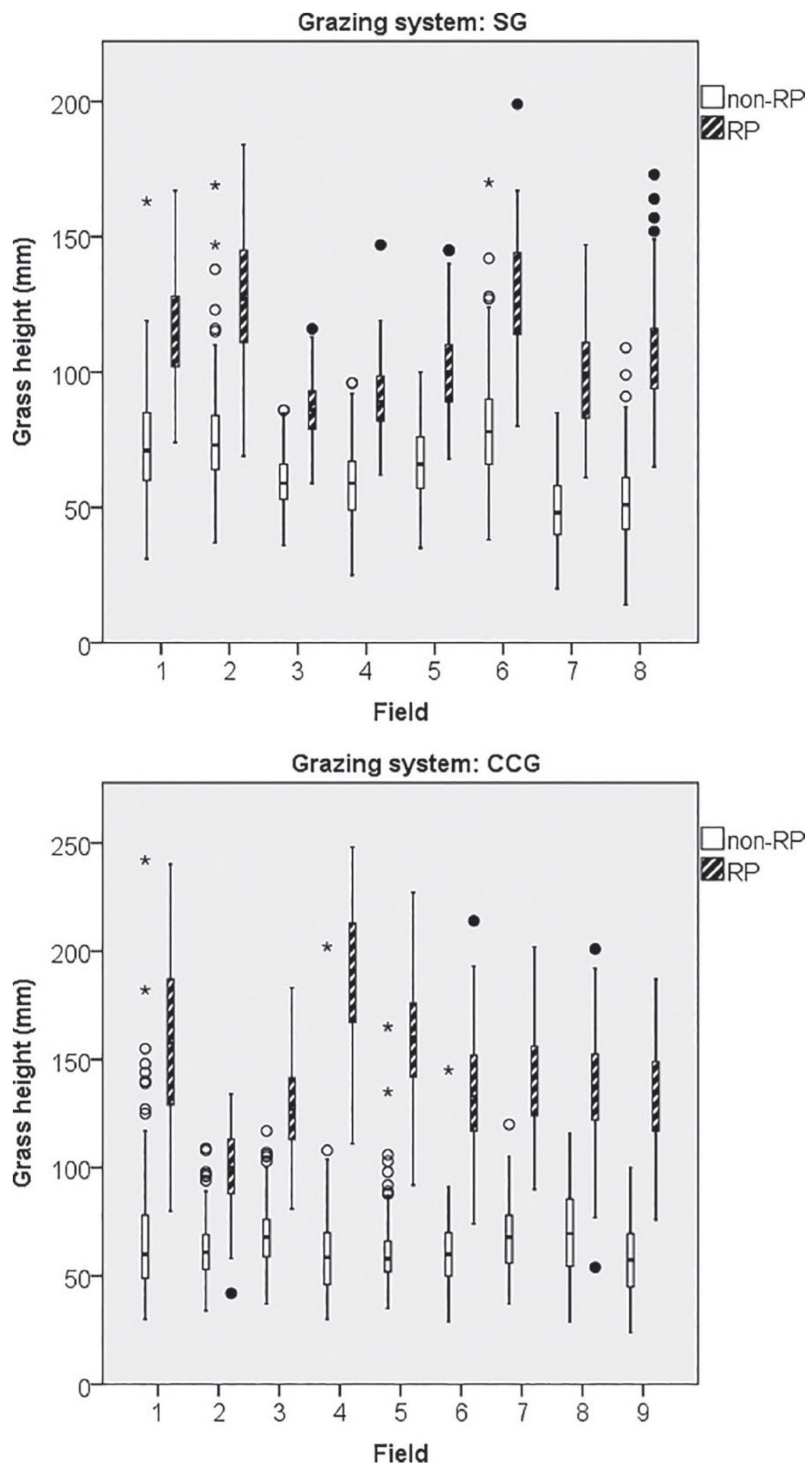

Figure 3. Range in grass height $(\mathrm{mm})$ per recently grazed field distinguishing between nonrejected patches (non-RP) and rejected patches (RP) split up for 2 grazing systems (i.e., $\mathrm{CCG}=$ compartmented continuous grazing and $\mathrm{SG}=$ strip grazing). The average grass height per field after grazing was higher for RP than for non-RP $(P<0.001)$. The boxes represent the interquartile (IQ) ranges, with lines for the median. The whiskers represent the lowest and highest values. The dots are the outliers (1.5-3 times the IQ range), and the asterisks are the extremes ( $>3$ times the IQ range). 


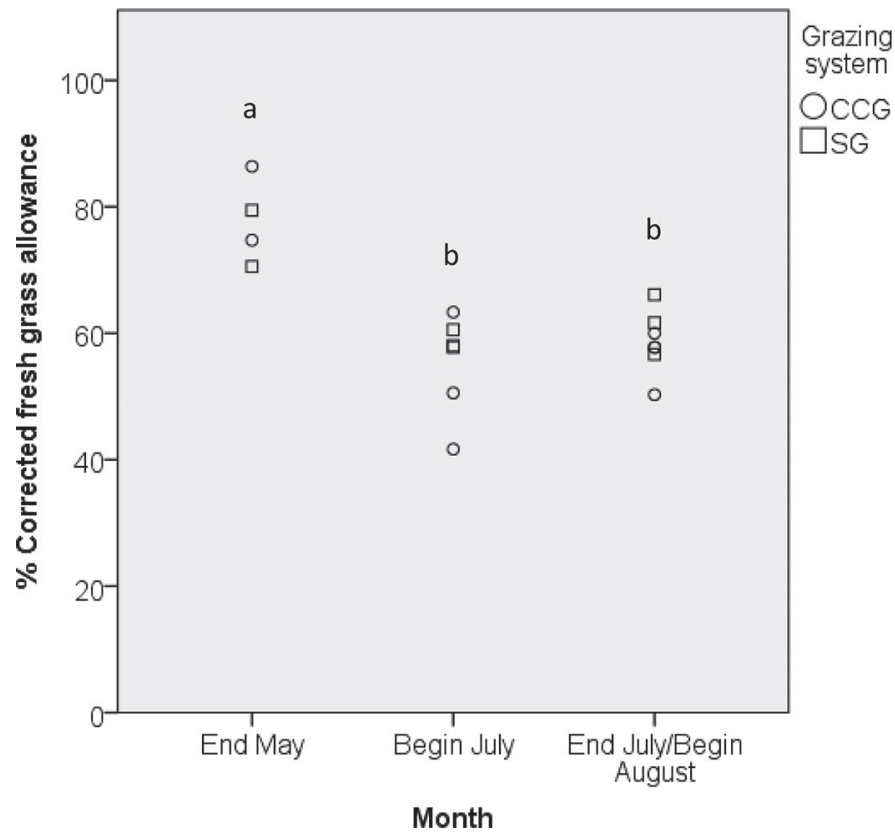

Figure 4. The percentage of fresh grass allowance remaining after correction for (i.e., excluding) rejected patches (RP) at the end of May, beginning of July, and end of July/beginning of August for continuous compartmented grazing (CCG) and strip grazing (SG). Different letters indicate significant differences $(P<0.001)$.

grass height between non-RP and RP decreases with an increase in the number of days since grazing. For grazing systems with a long grazing interval (i.e., SG), the contrast between non-RP and RP will be small if the RP cannot be visually distinguished and, therefore, will not substantially affect the average grass height.

Table 1. Number of grass height measurements needed in fields for compartmented continuous grazing (CCG) and strip grazing (SG) systems to reach various levels of accepted error when estimating average grass height

\begin{tabular}{lrr}
\hline & \multicolumn{2}{c}{ No. of grass height measurements } \\
\cline { 2 - 3 } $\begin{array}{l}\text { Accepted error } \\
\text { (mm of grass) }\end{array}$ & CCG & SG \\
\hline 1 & 2,089 & 2,375 \\
2 & 522 & 594 \\
3 & 232 & 264 \\
4 & 131 & 148 \\
5 & 84 & 95 \\
6 & 58 & 66 \\
7 & 43 & 48 \\
8 & 33 & 37 \\
9 & 26 & 29 \\
10 & 21 & 24 \\
11 & 17 & 20 \\
12 & 15 & 16 \\
13 & 12 & 14 \\
14 & 11 & 12 \\
15 & 9 & 11 \\
\hline
\end{tabular}

In this case, the surface correction will be sufficient to correct fresh grass allowance for the formation of RP.

Quantifying the surface covered with RP can be done during the grass height measurements with the RPM. This requires scoring the number of measurements that corresponds with an RP (yes/no) based on visual assessment, as in this study. Due to the increase in RP during the season it is advisable to do this in spring and summer in a representative subset of the field. In addition, RP should be excluded from the weekly grass height measurements if they can be visually distinguished to get a more accurate average grass height. Since this method is labor intensive, it might be more practical to explore less labor-intensive methods, for example the potential of multispectral images to correct fresh grass allowance for selective grazing.

\section{Required Number of Grass Height Measurements Per Field}

Table 1 shows the effect of number of grass height measurements on the accuracy of average grass height estimates per field for CCG and SG. The number of necessary grass height measurements decreases with a decrease in within-field variance and with an increase in accepted error. The within-field variance in grass height before grazing was $544 \mathrm{~mm}^{2}$ for CCG and 618 $\mathrm{mm}^{2}$ for SG. The current advice in practice is to take 30 measurements per field before grazing to estimate fresh grass allowance (Holshof and Stienezen, 2016). The corresponding errors in estimations of the average grass height per field are 8 to $9 \mathrm{~mm}$ for both CCG and SG. The error in estimating the average grass height should in general be as small as possible since the calculation from average grass height to HM already comes with an error margin of 25 to $31 \%$ under CCG and SG (Klootwijk et al., 2019). Since most of the RPM measure grass height in clicks, which corresponds with $5 \mathrm{~mm}$, this might be accepted as a maximal error. To achieve a maximal error of $5 \mathrm{~mm}$, our results indicate that we need to take minimally 84 measurements per field in CCG, when excluding visible RP, and 95 measurements per field in SG.

\section{CONCLUSIONS}

Our analysis showed that the average percentage of grassland (predominantly perennial ryegrass) covered with RP increased from around $22 \%$ at the end of May to around $43 \%$ at the end of July/beginning of August at a fixed stocking rate of $7.5 \mathrm{cow} / \mathrm{ha}$. After a period of increase in grassland covered with $\mathrm{RP}$ an equilibrium state was reached, which can be explained 
by a balance between formation of RP due to excreta and reduction of RP due to breakdown of dung. We found no difference between grazing systems in average proportion of RP and development of RP over the season. Our finding that on average 22 to $43 \%$ of the grassland is covered with RP indicates that estimates of grass height should be corrected for RP formation in intensive grazing systems when estimating potential fresh grass allowance. This can be done by subtracting the percentage of grassland covered with RP from the total grazed area. Our results suggest that the percentage of grassland covered with RP is not influenced by grazing system under intensive grazing in perennial ryegrass pastures and, therefore, the surface correction can be used across grazing systems. If the RP can be visually distinguished before grazing, they should be excluded from the grass height measurements to get a reliable estimate of the remaining grazing area without $\mathrm{RP}$. This is more relevant for grazing systems with a short grazing interval (i.e., CCG) since the contrast in grass height between non-RP and RP reduces with an increased period of regrowth. For grazing systems with a long grazing interval (i.e., SG), the contrast between non-RP and RP will be small if the RP cannot be visually distinguished and, therefore, will not substantially affect the average grass height. The current advice in practice is to take 30 measurements per field before grazing to estimate fresh grass allowance. To achieve a maximal error of $5 \mathrm{~mm}$, our results indicate to take a minimum of 90 measurements per field in intensive grazing systems.

\section{ACKNOWLEDGMENTS}

This work is part of the research program financed by the Province of Fryslân (Leeuwarden, the Netherlands). In addition, this work was carried out within the framework of the Amazing Grazing project (www .amazinggrazing.eu), which is financed by ZuivelNL, LTO, NZO, and the Dutch Ministry of Agriculture, Nature and Food Quality (Den Haag, the Netherlands). We thank the financers of this research and the employees at Dairy Campus for their assistance during the field work.

\section{REFERENCES}

Arnold, G. W., and W. Holmes. 1958. Studies in grazing management. VII. The influence of strip grazing versus controlled free grazing on milk yield, milk composition, and pasture utilization. J. Agric. Sci. 51:248-256. https://doi.org/10.1017/S0021859600034250.

Bao, J., P. S. Giller, and G. Stakelum. 1998. Selective grazing by dairy cows in the presence of dung and the defoliation of tall grass dung patches. Anim. Sci. 66:65-73. https://doi.org/10.1017/ S1357729800008845.
Blokland, P. W., A. Van den Pol-Dasselaar, C. Rougoor, F. Van der Schans, and L. Sebek. 2017. Maatregelen om weidegang te bevorderen; Inventarisatie en analyse (Measures to stimulate grazing; Inventarisation and analysis). Wageningen University \& Research, report 071, Wageningen, the Netherlands.

Boogaard, B., B. Bock, S. Oosting, and E. Krogh. 2010. Visiting a farm: An exploratory study of the social construction of animal farming in Norway and the Netherlands based on sensory perception. Int. J. Sociol. Agric. Food 17:24-50.

Bosker, W. T. E., N. J. Hoekstra, and E. A. Lantinga. 2002. The influence of feeding strategy on growth and rejection of herbage around dung pats and their decomposition. J. Agric. Sci. 139:213-221. https://doi.org/10.1017/S0021859602002472.

Castle, M. E., and E. MacDaid. 1972. The decomposition of cattle dung and its effect on pasture. Grass Forage Sci. 27:133-138. https://doi.org/10.1111/j.1365-2494.1972.tb00700.x.

Dennis, S. J., J. L. Moir, K. C. Cameron, H. J. Di, D. Hennessy, and K. G. Richards. 2011. Urine patch distribution under dairy grazing at three stocking rates in Ireland. IJAFR 50:149-160.

Dohi, H., A. Yamada, and S. Entsu. 1991. Cattle feeding deterrents emitted from cattle feces. J. Chem. Ecol. 17:1197-1203. https:// doi.org/10.1007/BF01402943.

Doornewaard, G. J., J. W. Reijs, A. C. G. Beldman, J. H. Jager, and M. W. Hoogeveen. 2017. Sectorrapportage Duurzame Zuivelketen; Prestaties 2016 in perspectief (Sector report Duurzame Zuivelketen; Achievements 2016 in perspective). Wageningen Economic Research, report 087, Wageningen, the Netherlands.

Finneran, E., P. Crosson, P. O'Kiely, and L. Shalloo. 2012. Stochastic simulation of the cost of home-produced feeds for ruminant livestock systems. J. Agric. Sci. 150:123-139. https://doi.org/10 $.1017 /$ S002185961100061X.

Hennessy, D., L. Delaby, A. Van den Pol-Dasselaar, and L. Shalloo. 2015. Possibilities and constraints for grazing in high output dairy systems. Pages 151-162 in Proc. Grassland Science in Europe 20.

Holshof, G., and M. W. J. Stienezen. 2016. Grasgroei meten met de grashoogtemeter. Wageningen University \& Research, Livestock Research, Report 925, Wageningen, the Netherlands.

Holshof, G., R. L. G. Zom, A. P. Philipsen, A. Van Den Pol-Van Dasselaar, and C. W. Klootwijk. 2018. Amazing grazing: substantial fresh grass intake in restricted grazing systems with high stocking rates. Pages 234-236 in Proc. Grassland Science in Europe 23

Kennedy, E., M. O'Donovan, J. P. Murphy, L. Delaby, and F. P. O'Mara. 2007. Effect of spring grazing date and stocking rate on sward characteristics and dairy cow production during midlactation. J. Dairy Sci. 90:2035-2046. https://doi.org/10.3168/jds.2006 -368 .

Klootwijk, C. W., G. Holshof, A. van den Pol-van Dasselaar, K. L. M. van Helvoort, B. Engel, I. J. M. de Boer, and C. E. van Middelaar. 2019. The effect of intensive grazing systems on the rising plate meter calibration for perennial ryegrass pastures. J. Dairy Sci. 102:10439-10450. https://doi.org/10.3168/jds.2018-16118.

Lantinga, E., J. Keuning, J. Groenwold, and P. Deenen. 1987. Distribution of excreted nitrogen by grazing cattle and its effects on sward quality, herbage production and utilization. Pages 103-117 in Animal Manure on Grassland and Fodder Crops. Fertilizer or Waste? Springer, Berlin, Germany.

MacLusky, D. S. 1960. Some estimates of the areas of pasture fouled by the excreta of dairy cows. Grass Forage Sci. 15:181-188. https: //doi.org/10.1111/j.1365-2494.1960.tb00176.x.

Marten, G. C., and J. D. Donker. 1964. Selective grazing induced by animal excreta I. Evidence of occurrence and superficial remedy. J. Dairy Sci. 47:773-776. https://doi.org/10.3168/jds.S0022 -0302(64)88762-2.

McCullagh. P., and J. A. Nelder. 1989. Generalized Linear Models. 2nd ed. Chapman \& Hall, London, UK.

Meul, M., S. Van Passel, D. Fremaut, and G. Haesaert. 2012. Higher sustainability performance of intensive grazing versus zero-grazing dairy systems. Agron. Sustain. Dev. 32:629-638. https://doi.org/ 10.1007/s13593-011-0074-5.

Sanderson, M. A., C. A. Rotz, S. W. Fultz, and E. B. Rayburn. 2001. Estimating forage mass with a commercial capacitance meter, ris- 
ing plate meter, and pasture ruler. Agron. J. 93:1281-1286. https: //doi.org/10.2134/agronj2001.1281.

Schwinning, S., and A. J. Parsons. 1999. The stability of grazing systems revisited: Spatial models and the role of heterogeneity. Funct. Ecol. 13:737-747. https://doi.org/10.1046/j.1365-2435.1999.00382 .x.

Stockdale, C. R., and K. R. King. 1983. Effect of stocking rate on the grazing behaviour and faecal output of lactating dairy cows. Grass Forage Sci. 38:215-218. https://doi.org/10.1111/j.1365-2494.1983 .tb01642.x.

Vadas, P., S. Aarons, D. Butler, and W. Dougherty. 2011. A new model for dung decomposition and phosphorus transformations and loss in runoff. Soil Res. 49:367-375. https://doi.org/10.1071/ SR10195.

Van den Pol-van Dasselaar, A., A. P. Philipsen, and M. H. A. De Haan. 2014. Economics of grazing. Pages 662-664 in Proc. Grassland Science in Europe 19.

Van den Pol-van Dasselaar, A., P. W. Blokland, T. J. A. Gies, G. Holshof, M. H. A. D. Haan, H. S. D. Naeff, and P. Philipsen. 2015. Beweidbare oppervlakte en weidegang op melkveebedrijven in Nederland (Grazing platform and grazing on dairy farms in the Netherlands). Wageningen UR (University \& Research centre) Livestock Research, Livestock Research, Wageningen, the Netherlands.

Van den Pol-van Dasselaar, A., T. V. Vellinga, A. Johansen, and E. Kennedy. 2008. To graze or not to graze, that's the question. Pages 706-716 in Proc. Grassland Science in Europe 13.

Van Schooten, H. A., K. M. Van Houwelingen, A. P. Philipsen, N. J. M. Van Eekeren, and F. A. J. Lenssinck. 2014. Amazing Grazing deelproject: De Weidewasser 2013: innovatievraag: Hogere opbrengst en lagere verliezen van grasland?: opgave: Negatief effect van mestflatten omzetten in positief effect. Wageningen UR Livestock Research, Lelystad, the Netherlands.

Verwer, C., H. Van Schooten, B. Philipsen, F. Lennsinck, K. Van Houwelingen, and N. Van Eekeren. 2016. Rejection of grass around dung pats; influence of smell, taste or both? Pages 430-432 in Proc. Grassland Science in Europe 21.

VSN International. 2017. Genstat for Windows 19th ed. VSN International, Hemel Hempstead, UK. Genstat.co.uk. 